EESTI NSV TEADUSTE AKADEEMIA TOIMETISED. 19. KOIDE

KEEMIA * GEOLOOGIA. 1970, NR. 3

ИЗВЕСТИЯ АКАДЕМИИ НАУК ЭСТОНСКОИ ССР. ТОМ 19

ХИМИЯ * ГЕОЛОГИЯ. 1970, № 3

A. СОКОЛОВЕР

\title{
ЗАВИСИМОСТИ МЕЖДУ ПОКАЗАТЕЛЯМИ КАЧЕСТВА ГОРЮЧИХ СЛАНЦЕВ
}

Разрабатываемые в настоящее время некоторые направления в использовании горючих сланцев Прибалтики (например, энерготехнологическое, энергоклинкерное, сжигание с жидким шлакоудалением) предусматривают утилизацию их органической и минеральной частей. Вследствие этого возникает ряд требований к качеству и вещественному составу товарного сланца, дополнительных к требованиям действующих ГОСТов и технических условий.

Получение товарного продукта, прнгодного для использования его органической и минеральной частей, ограничено, с одной стороны, природными свойствами полезного ископаемого, а с другой - способами его подготовки.

Для решения вопроса о возможности получения в промышленном масштабе требуемого продукта необходимо знание количественных зависимостей между различными показателями качества и вещественного состава товарного сланца.

К числу основных показателей, представляющих интерес для комплексного использования энергетического сланца, относятся: калорийность абсолютно-сухого сланца по бомбе $-Q_{6}^{c}$, низшая калорийность горючей массы $-Q_{\text {н }}^{\text {r }}$, низшая калорийность рабочего топлива $-Q_{\text {н }}^{\mathrm{p}}$, содержание двуокиси углерода карбонатов в абсолютно-сухом сланце $\left(\mathrm{CO}_{2}\right)_{\kappa}^{c}$, зольность абсолютно-сухого сланца - $A^{\circ}$, компоненты химического состава зольного остатка - $\mathrm{CaO}, \mathrm{MgO}, \mathrm{SiO}_{2}, \mathrm{Fe}_{2} \mathrm{O}_{3}, \mathrm{Al}_{2} \mathrm{O}_{3}, \mathrm{TiO}_{2}$ н $\mathrm{SO}_{3}$.

В настоящей статье изложены результаты изучения изменения этих показателей. Исходным материалом служили технические анализы и анализы зольного остатка товарного энергетического сланца с предприятий треста Эстонсланец по единичным пробам, отобранным Институтом геологии АН Эстонской ССР на Прибалтийской ГРЭС (Соколовер, 1970).

При исследовании зависимостей в качестве аргументов были приняты $A^{\mathrm{c}}$ и $\mathrm{Q}_{6}^{\mathrm{c}}$. Зольность применяется в качестве аргумента в работах Всесоюзного теплотехнического института им. Ф. Э. Дзержинского при определении средних величин различных показателей. Целесообразность использования калорийности $Q_{\sigma}^{c}$ в качестве аргумента обусловлена тем, что по ней, как основному показателю товарного сланца по ГОСТам и техническим условиям, накоплен значительный фактический материал. 
Аппроксимация изучаемых зависимостей производилась линейными $(y=a x+c)$, неполными квадратичными $\left(y=b(x-\bar{x})^{2}+c\right)$ и полными квадратичными $\left(y=a x+b(x-\bar{x})^{2}+c\right)$ уравнениями (Иенк, Опер, 1966). Учитывались зависимости, для которых нулевая гипотеза (отсутствие связей между изучаемыми величинами) отвергалась с вероятностью 95 и более процентов.

Все изученные связи, за исключением зависимостей $Q_{\text {н }}^{\text {г }}$ о $A^{\text {c }}$ и $Q_{6}^{c}$, оказались значимыми и для этих функций произведен прогноз значений при различных величинах аргументов, заключавшийся в нахождении оценок наиболее вероятных значений средних величин, пределов их колебаний и колебаний показателей качества по единичным пробам для $95 \%$-го уровня значимости. Вычисления проводились по программе M. Каролин (1966). Графическая интерпретация соответствующих вычислений дана на рис. 1, 2. Приведенные на графиках линии показывают изменение наиболее вероятных значений средних величин, пределы их колебаний н пределы колебаний значений показателей качества единичных проб, отобранных Институтом геологии на Прибалтийской ГРЭС. На графики нанесены также фактические значения наблюденных величин. В надписях к графикам приведены принятые уравнения регрессии (со стандартными ошибками их коэффициентов) и соответствующие коэффициенты множественной корреляции.

В целях выяснения природы полученных зависимостей в зольном остатке выделены карбонатная составляющая - $K$ и некарбонатная (преимущественно терригенная составляющая) - Тер. Tep $+K=100 \%$. Максимальное долевое участие в зольном остатке некарбонатной составляющей приурочено $\mathrm{K} A^{\mathrm{c}} \approx 46 \%$. В то же время Тер с ростом $Q_{6}^{\mathrm{c}}$ на изученном участке $\left(Q_{6}^{c}=1940 \div 3490 \frac{\kappa \kappa a \Omega}{\kappa 2}\right)$ возрастает и теоретически достигает максимума при $Q_{\sigma}^{c} \approx 3550 \frac{\kappa \kappa a \Omega}{\kappa 2}$. Однако $A^{c} \approx 46 \%$ соответствует наиболее вероятное значение $Q_{6}^{c} \approx 3200$, а не $3550 \frac{\kappa \kappa a \Omega}{\kappa 2}$. Такая «неувязка» является отражением противоречивости регрессионного анализа. Практически, видимо, имеет смысл говорить о зоне значительного преобладания в зольном остатке некарбонатной составляющей. Эта зона охватывает в асновном сланец с $Q_{\sigma}^{c}=3100 \div 3600 \frac{\kappa \kappa a \Omega}{\kappa 2}$. Данный интервал является также участком пониженного содержания в зольном остатке карбонатной составляющей.

Различные компоненты химического состава зольного остатка в неодинаковой степени связаны с его карбонатной и некарбонатной составляющими.

$\mathrm{CaO}$ связан в өсновном с его карбонатной составляющей. Так, по 27 пробам общее содержание $\mathrm{CaO}$ в золе равно $48,9 \%$, из них на долю карбонатной $\mathrm{CaO}$ приходится $48,5 \%$, а на долю терригенной - $0,4 \%$. Вследствие данного обстоятельства и убывающей зависимости теплотворной спссобности от содержания карбонатов в золе, зависимость $\mathrm{CaO}$ в золе от $Q_{6}^{c}$ также является убывающей, а от величины зольности - возрастающей. $\mathrm{MgO}$ также связан в основном с карбонатами. По тем же пробам в среднем имеем: общее содержание $\mathrm{MgO}$ в золе - 4,8\%, в том числе карбонатной - 3,4\% и терригенной - 1,4\%. Зависимости содержания MgO в золе от $Q_{6}^{c}$ и от величины зольности имеют естественные минимумы, приуроченные к зоне пониженного содержания в зольном остатке карбонатной составляющей. 
Остальные компоненты зольного остатка составляют его некарбонатную часть и некоторье из их зависимостей, например $\mathrm{SiO}_{2}, \mathrm{Al}_{2} \mathrm{O}_{3}, \mathrm{SO}_{3}$ от $A^{c}$, имеют ясно выраженные максимумы, приуроченные к зоне преобладания этой составляющей в золе. Поскольку в ряде случаев точка. максимума выходит за пределы изученных значений аргумента либ́о сами связи лучше аппроксимируются линейными, чем квадратичными уравнениями, то ряд других компонентов некарбонатной составляющей связан с аргументами монотәнными зависимостями: например, зависимости содержания $\mathrm{Fe}_{2} \mathrm{O}_{3}$ от $A^{\mathrm{c}}, \mathrm{Fe}_{2} \mathrm{O}_{3}, \mathrm{Al}_{2} \mathrm{O}_{3}$ от $Q_{6}^{\mathrm{c}}$.

Анализ приведенных в данной статье уравнений свидетельствует о том, что зависимости показателей качества от $Q_{6}^{c}$ носят в целом более простой характер, чем от $A^{c}$. В то время как все 11 зависимостей от $A$. целесообразно аппроксимировать полными квадратичными уравнениями, из 11 зависимостей от $Q_{6}^{c}$ только 7 обосновано аппроксимировать полными квадратичными уравнениями, остальные 4 зависимости достаточно хорошо аппроксимируются линейными уравнениями. Тем не менее зависимости от $Q_{6}^{\mathrm{c}}$ значимее зависимостей от $A^{\mathrm{c}}$ : $\left(R\right.$ для уравнений от $Q_{6}^{\mathrm{c}}$. в ссновном больше, чем для уравнений от $\left.A^{c}\right)$. Это объясняется: тем обстоятельством, что $Q_{6}^{c}$ является для горючих сланцев Прибалтики более комплексным показателем, чем $A^{\mathrm{c}}$, поскольку полнее учитывает наличие в них значительного количества карбонатов. Кроме того $Q_{6}^{c}$ обладает большей изменчивостью, чем $A^{\mathrm{c}}$ : по 72 пробам сланца с предприятий треста Эстонсланец коэффициент вариации для $Q_{6}^{c}$ составляет $12,8 \%$, а для $A^{\circ}-3,6 \%$.

Значительные отклонения экспериментальных точек относительно линий наиболее вероятных значений обусловлены крайней неоднородностью сланца, поступающего на Прибалтийскую ГРЭС. (Поставщики ГРЭС по тресту Әстонсланец охватывают 10 шахт и карьеров). Для более узких групп топлива, характеризующихся общностью технологии добычи и подготовки товарного продукта, колебания отдельных показателей качества будут меньшими, а зависимости, охарактеризованные в данной статье, - более значимыми. Изучение такнх групп. топлива намечено на будущее. Установленные же на данном этапе общие закономерности позволяют сделать вывод о том, что изменяя $Q_{6}^{c}$ товарного продукта, можно менять в определенной мере и другие его показатели, представляющие интерес для комплексного его использования.

\section{Л И Т Е Р Т У Р А}

Иенк А., О пе р У., 1966. Регрессионный анализ. В сб.: Программы для ЭЦВМ «Минск-2», Вып. 2. (Ин-т кибернетики АН Эстонской ССР), Таллин.

$\mathrm{Ka} \mathrm{poлин} \mathrm{М.,} \mathrm{1966.} \mathrm{Прогноз} \mathrm{значений} \mathrm{и} \mathrm{дисперсий} \mathrm{линейной} \mathrm{комбинации} \mathrm{выходов}$ при заданных значениях вхотов регрессионным анализом. В сб.: Программы для ӘЦВМ «Минск-2», Вып. 2 (Ин-т кибернетики АН Эстонской ССР), Таллин.

С ок олов в р А., 1970. О пригодности сланца, поступающего на Прибалтийскую ГРЭС, для сжигания с жидким шлакоудалением. Горючие сланцы, № 1, Таллин.
Ннститут геологии
Академии наук Эстонской ССР
Поступила в редакцию: 
$Q_{0}^{C} \frac{k K a n}{K T} Q_{0}^{C}=-(203,3 \pm 12,0) A^{C}-(17,3 \pm 5,8)(A-47,15)^{2}+12535 ;$

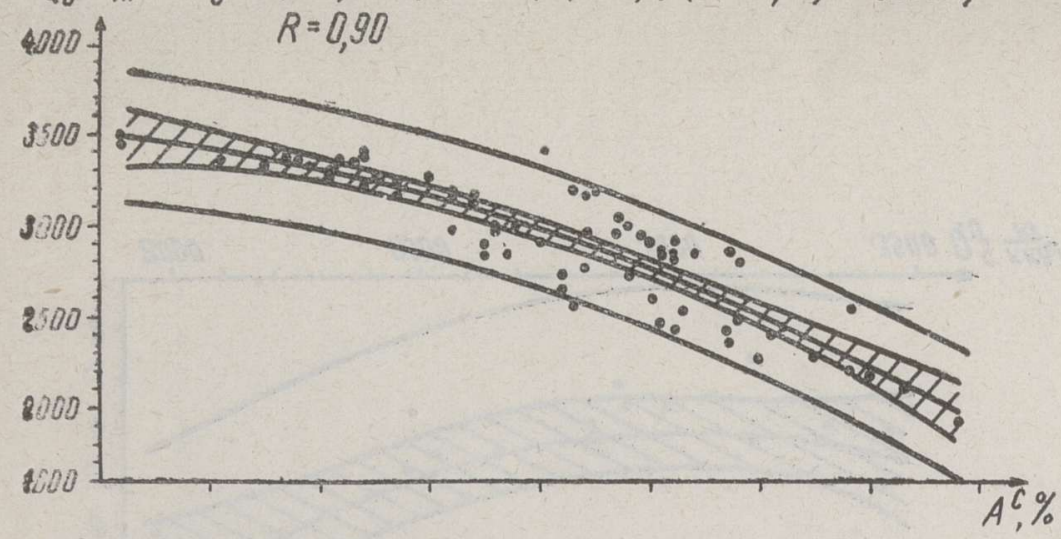

$Q_{H}^{\rho} \frac{K K a s}{K T} \dot{Q}_{H}^{p} \cdot-(155,9 \pm 8,1) A^{C}-(13,1 \pm 3,9)\left(A^{c}-47,15\right)^{2}+96.61$

so00 $\begin{aligned} Q^{\circ}-0,92 \\ R\end{aligned}$

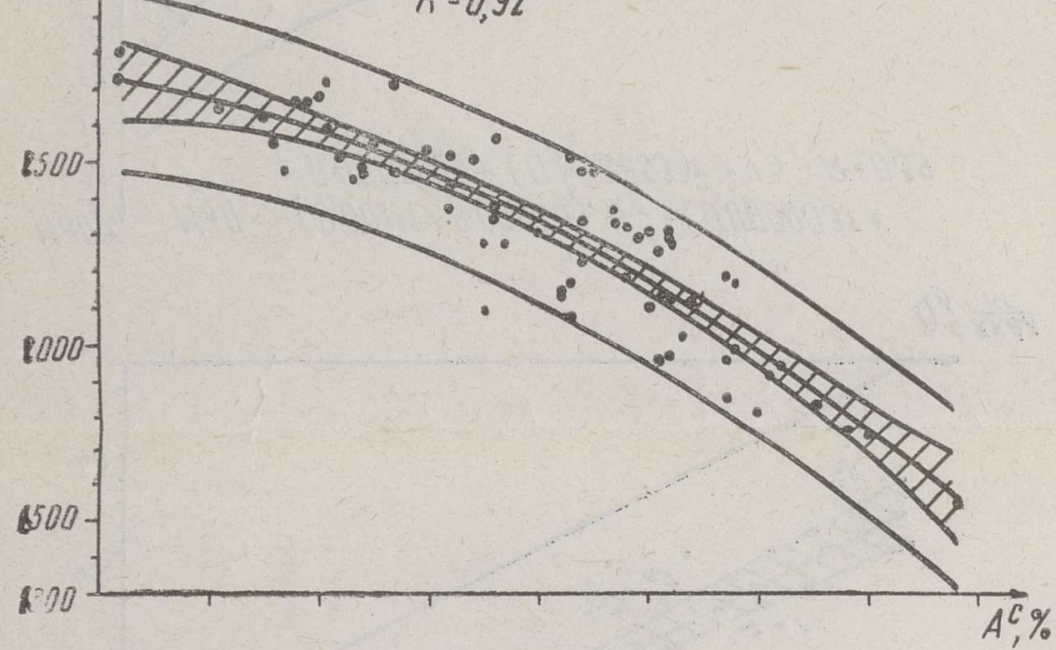

$\mathrm{CO}_{2}, \% \quad \mathrm{CO}_{2}=(1,15 \pm 0,12) A^{C}+(0,18 \pm 0,06)\left(A^{C}-47,15\right)^{2}$.
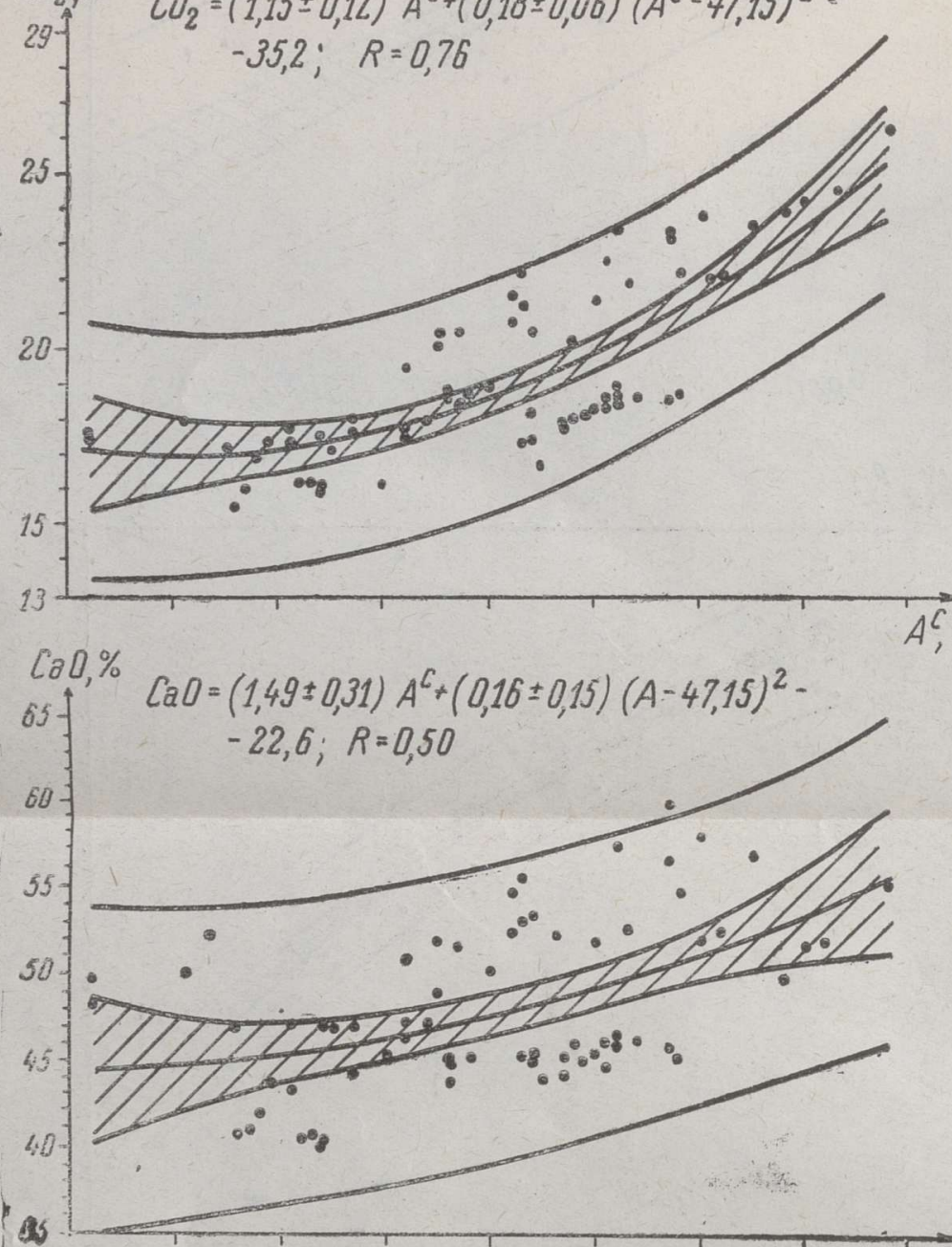

$A^{c} \%$

$M g 0 \% \quad M g O=(0,43 \pm 0,14) A^{\varepsilon}+(0,15 \pm 0,06)\left(A^{C}-47,36\right)^{2}-$

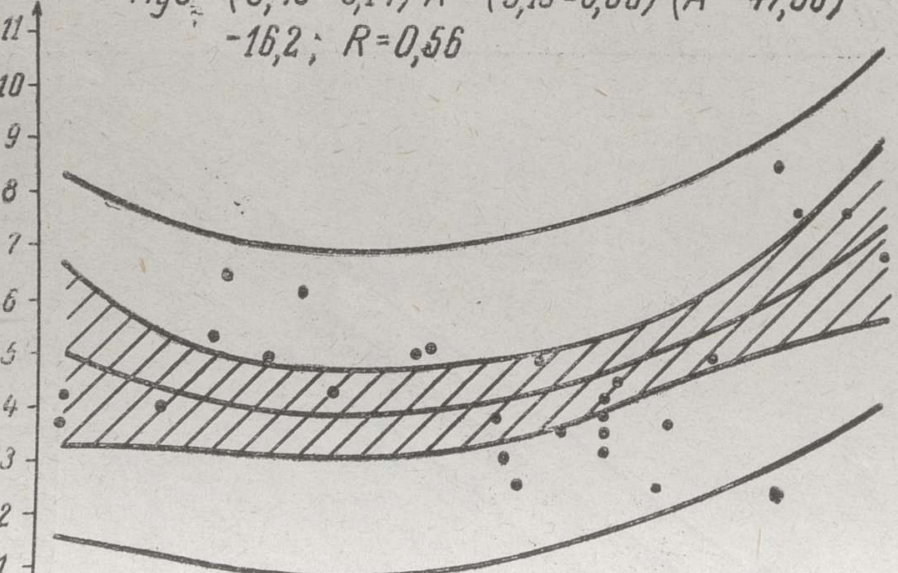

$A^{C} \%$

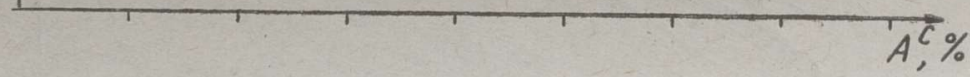

$\mathrm{SiO}_{2} \% \quad \mathrm{SiO}_{2}=-(0,84 \pm 0,25) A^{C}-(0,33 \pm 0,10)\left(A^{C}-47,36\right)^{2}+$

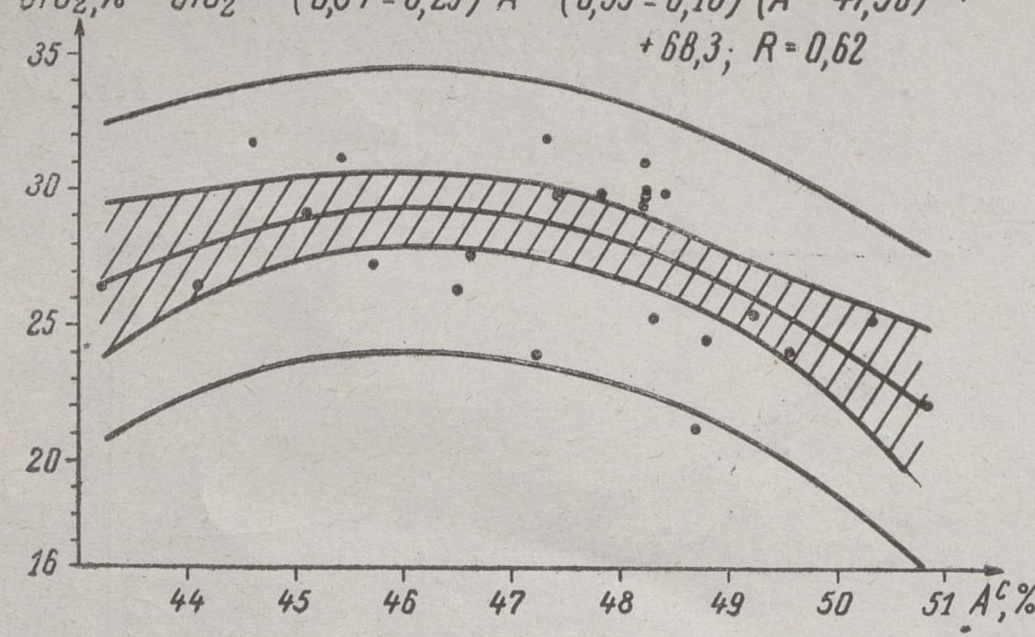

$\mathrm{Fe}_{2} \mathrm{O}_{3}, \% \quad \mathrm{Fe}_{2} \mathrm{O}_{3}=-(0,39 \pm 0,06) A^{C}-(0,05 \pm 0,03)\left(A^{C}-47,36\right)^{2}+$

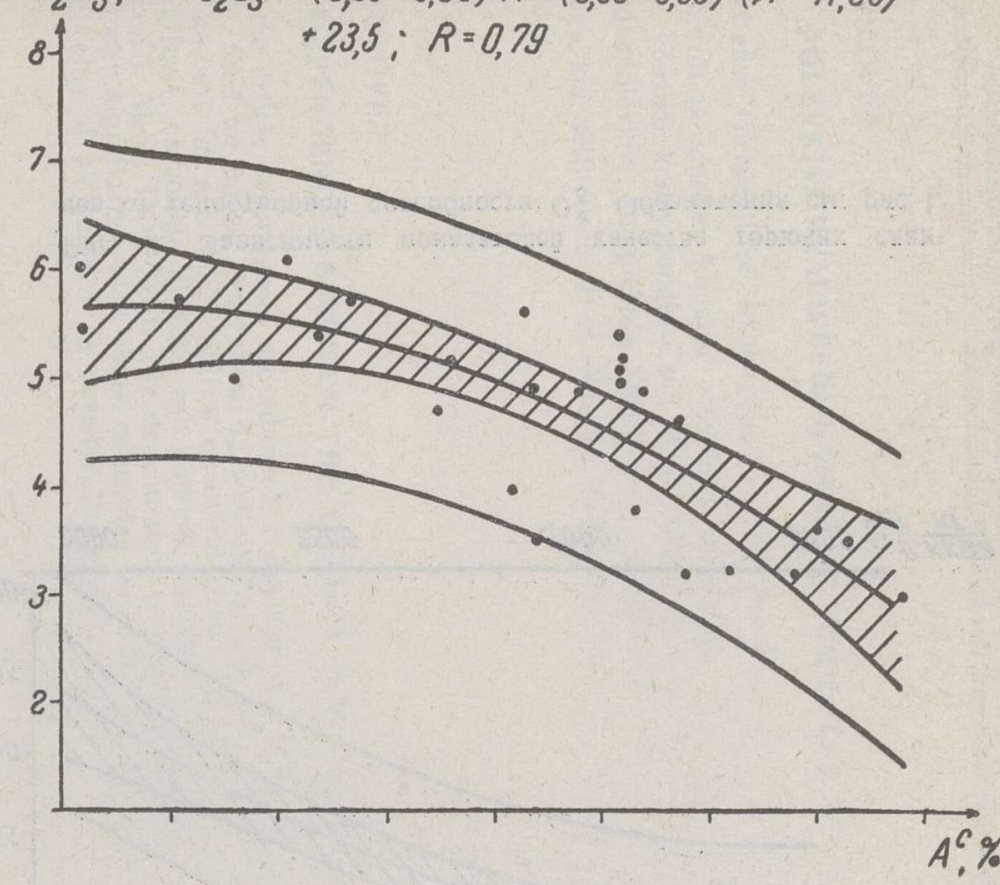

$A / 2 O_{3}, \% \quad A l_{2} O_{3}=-(0,22 \pm 0,08) A^{c}-(0,07 \pm 0,03)\left(A^{C}-47,36\right)^{2}+$

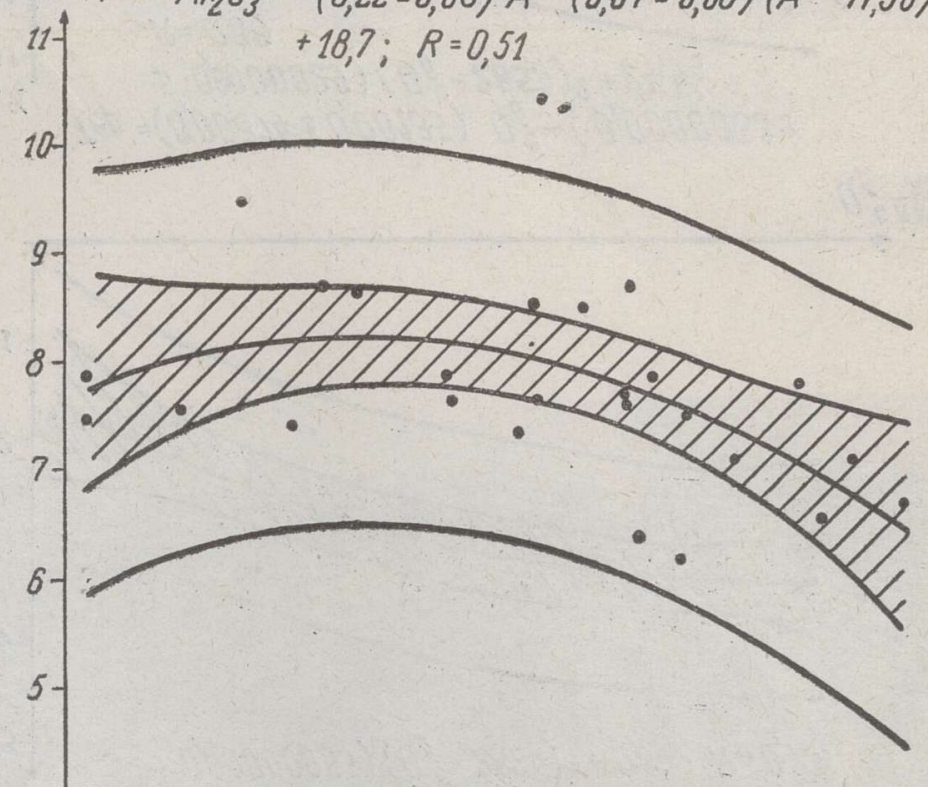

$\overrightarrow{A^{c} \%}$

$\mathrm{TiO}_{2} \% \mathrm{TiO_{2 }}=-(0,012 \pm 0,014) A^{C}-(0,014 \pm 0,006)\left(A^{C}-47,36\right)^{2}+$

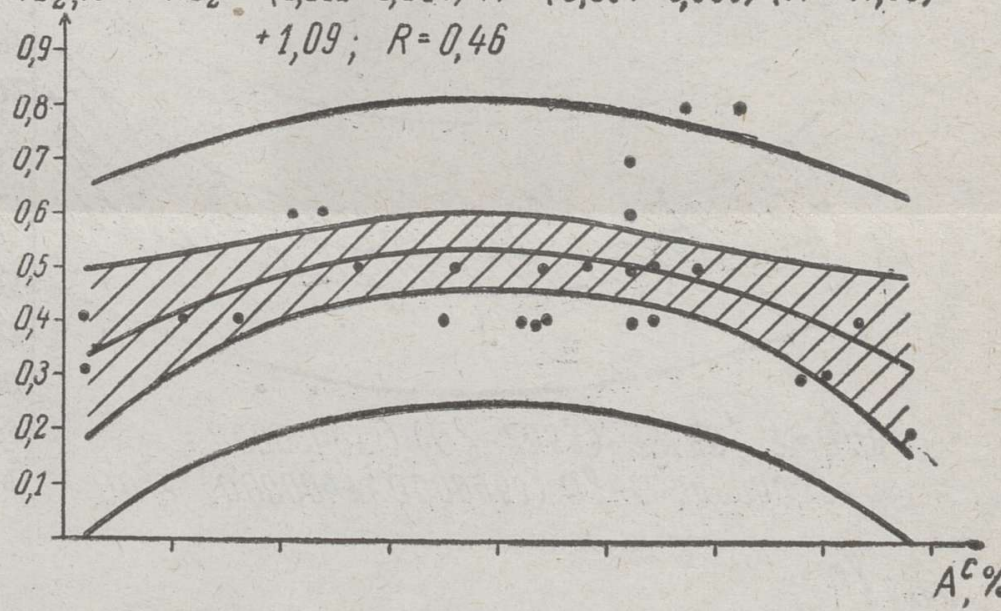

$\mathrm{SO}_{3} \% \quad \mathrm{SO}_{3}=-(0,25 \pm 0,05) A^{c}-(0,09 \pm 0,02)\left(A^{c}-47,31\right)^{2}$.

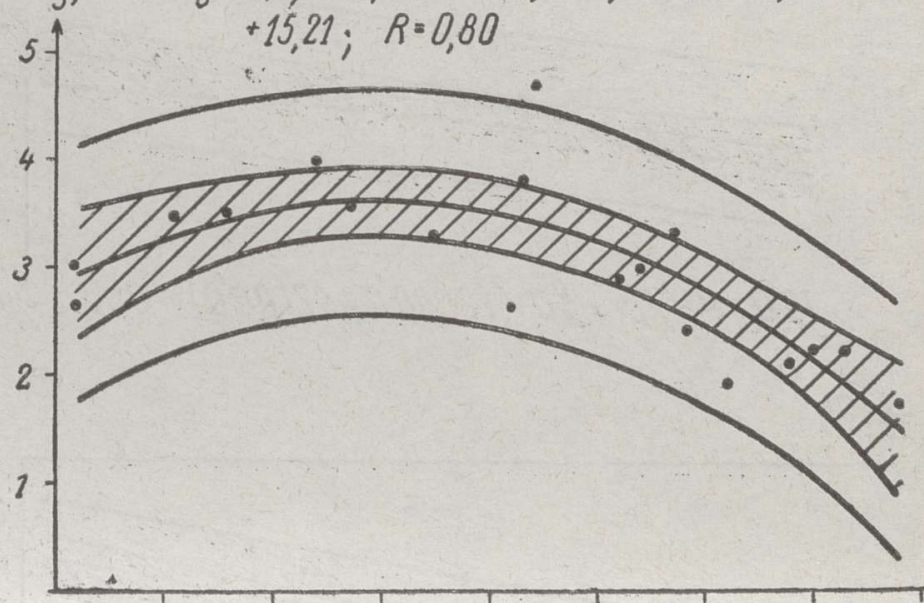

Tep,\% Tep $=-(1,89 \pm 0,39) A^{C}-(0,54 \pm 0,16)\left(A^{C}-47,36\right)^{2}+$

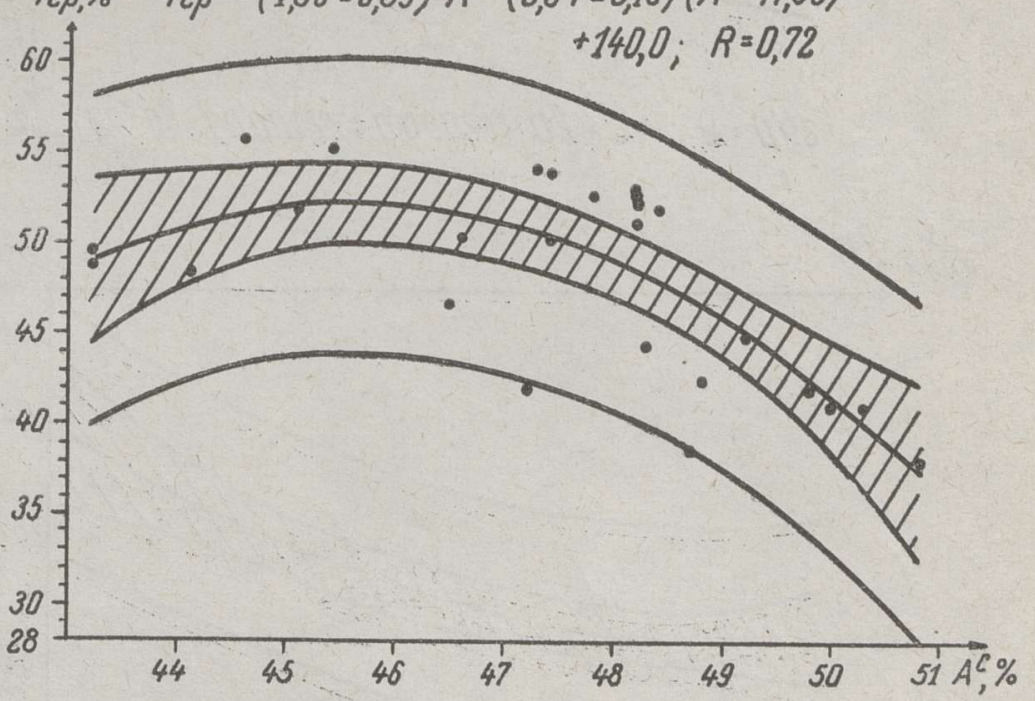

Рис. 1. Зависимости показателей качества горючих сландев от зольности $A^{\circ}, 1$ - среднее значение и пределы его коле 
$A_{1}^{C} \% \uparrow \quad A^{c}=-(0,00435 \pm 0,00026) Q_{\delta}^{c}-(0,0000020 \pm 0,0000006)$

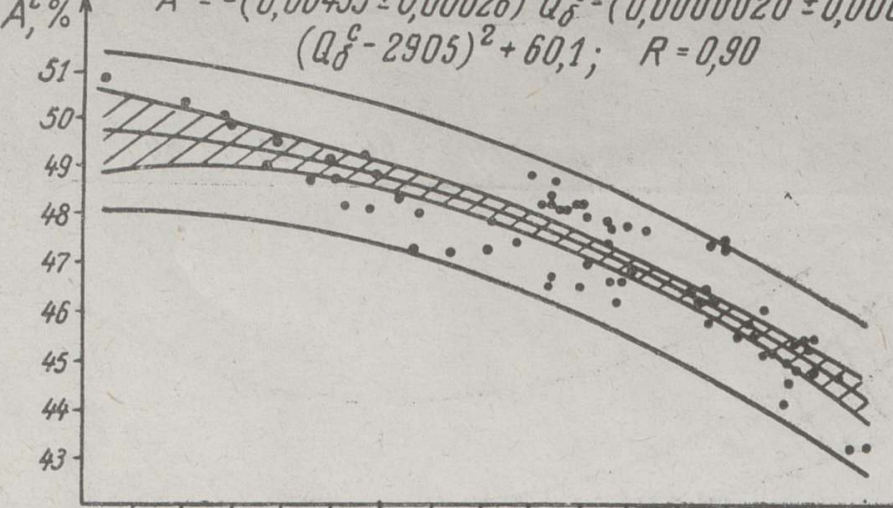

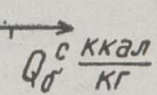

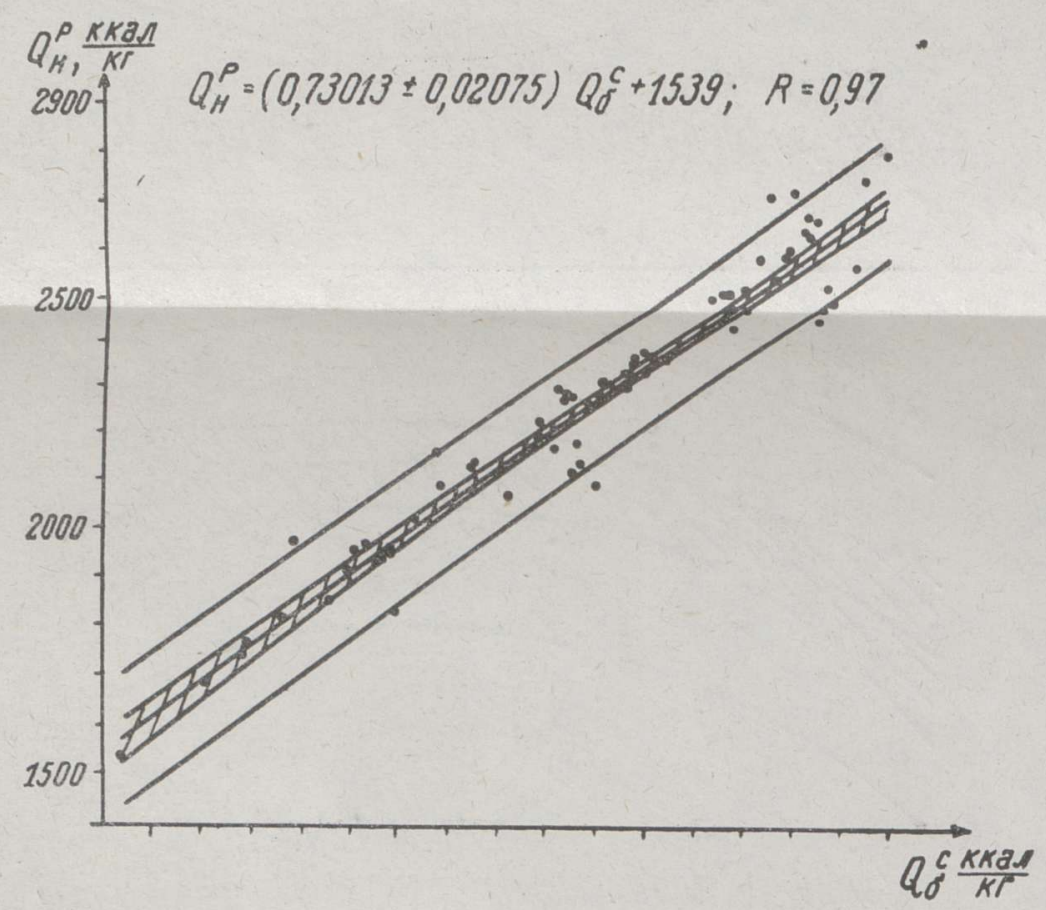

$\mathrm{CO}_{2}, \%, \quad \mathrm{CO}_{2}=-(0,00605 \pm 0,00024) Q_{0}^{c}+(0,0000020 \pm 0,0000005)$
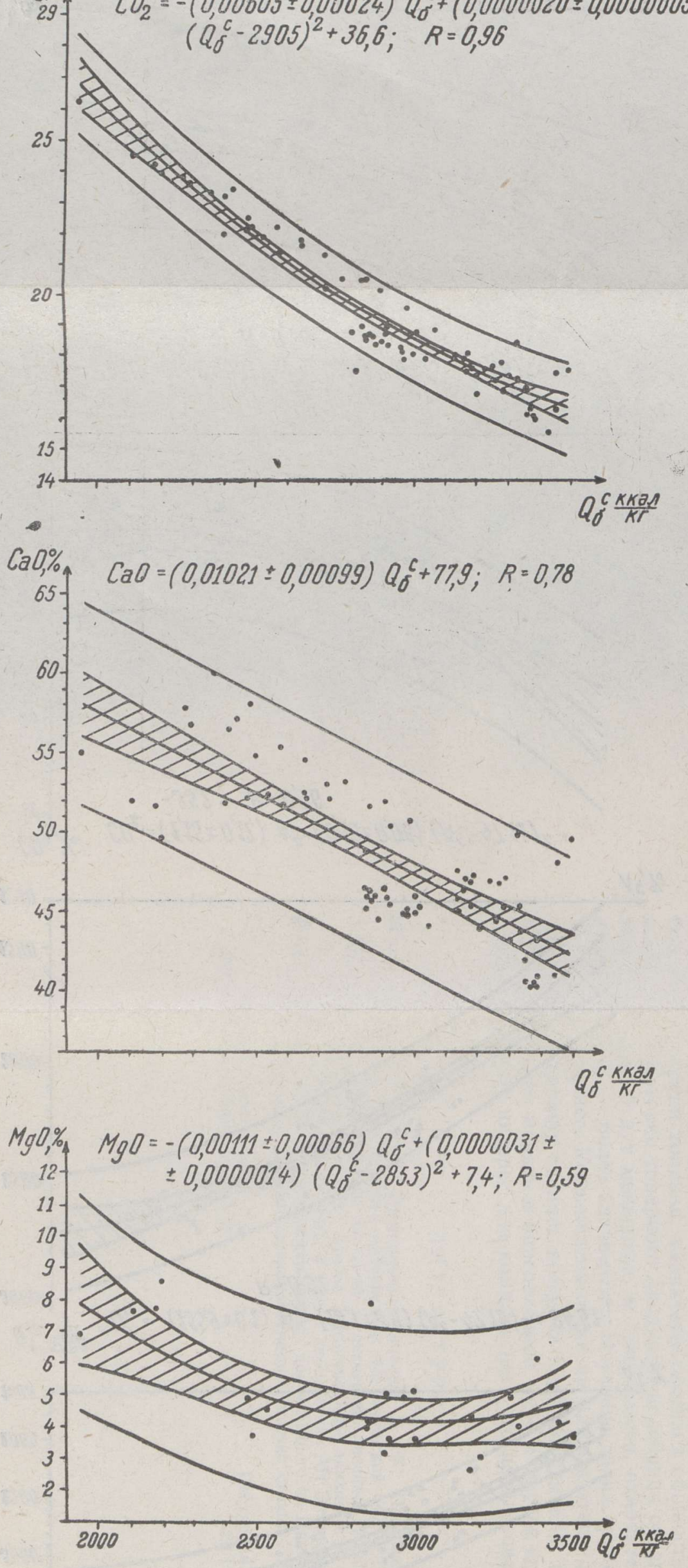

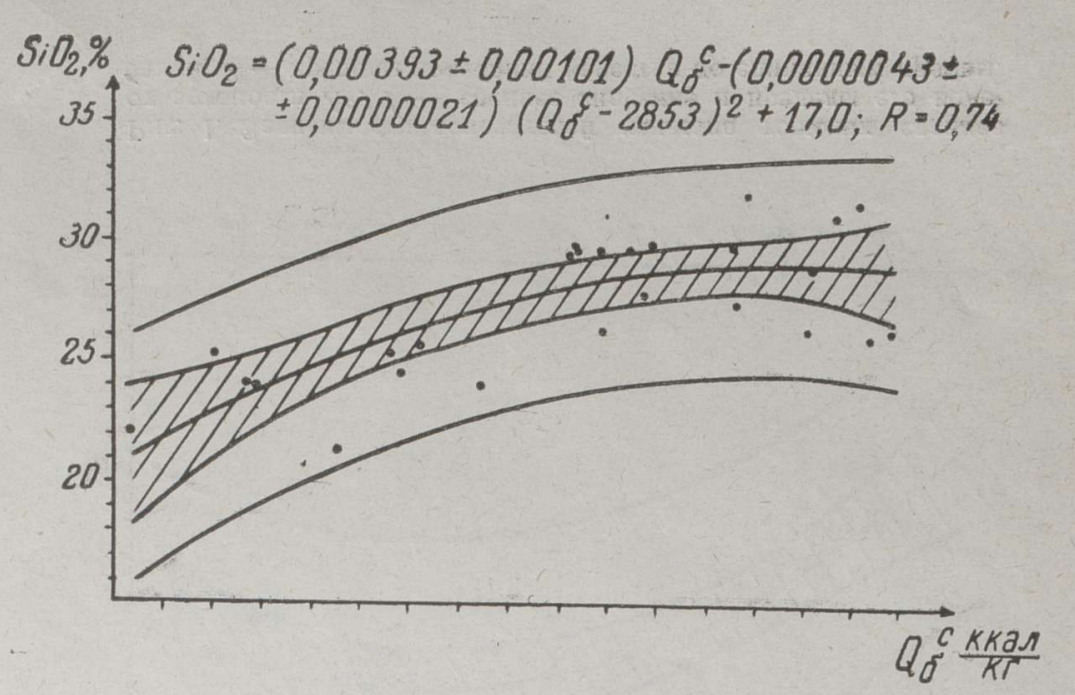

$\mathrm{Fe}_{2} \mathrm{O}_{3} \% \quad \mathrm{Fe}_{2} \mathrm{O}_{3}=(0,00177 \pm 0,00025) Q \mathrm{QE}^{\mathrm{E}}-0,4 ; R=0,82$
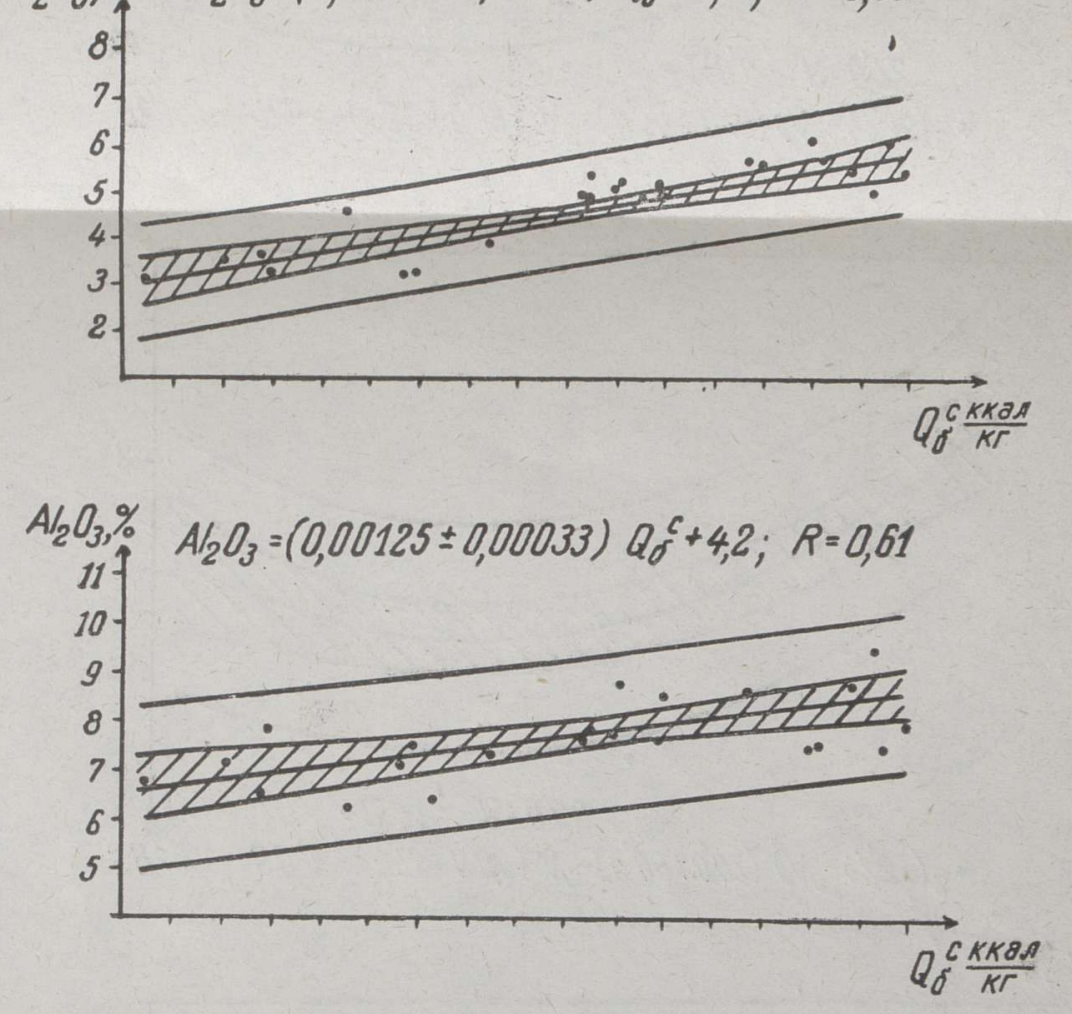

$\mathrm{TiO}_{2} \% \mathrm{\%} \quad \mathrm{TiO}_{2}=-(0,000043 \pm 0,000063) \mathrm{Q}_{\sigma}^{\mathrm{C}}-(0,00000035 \pm$
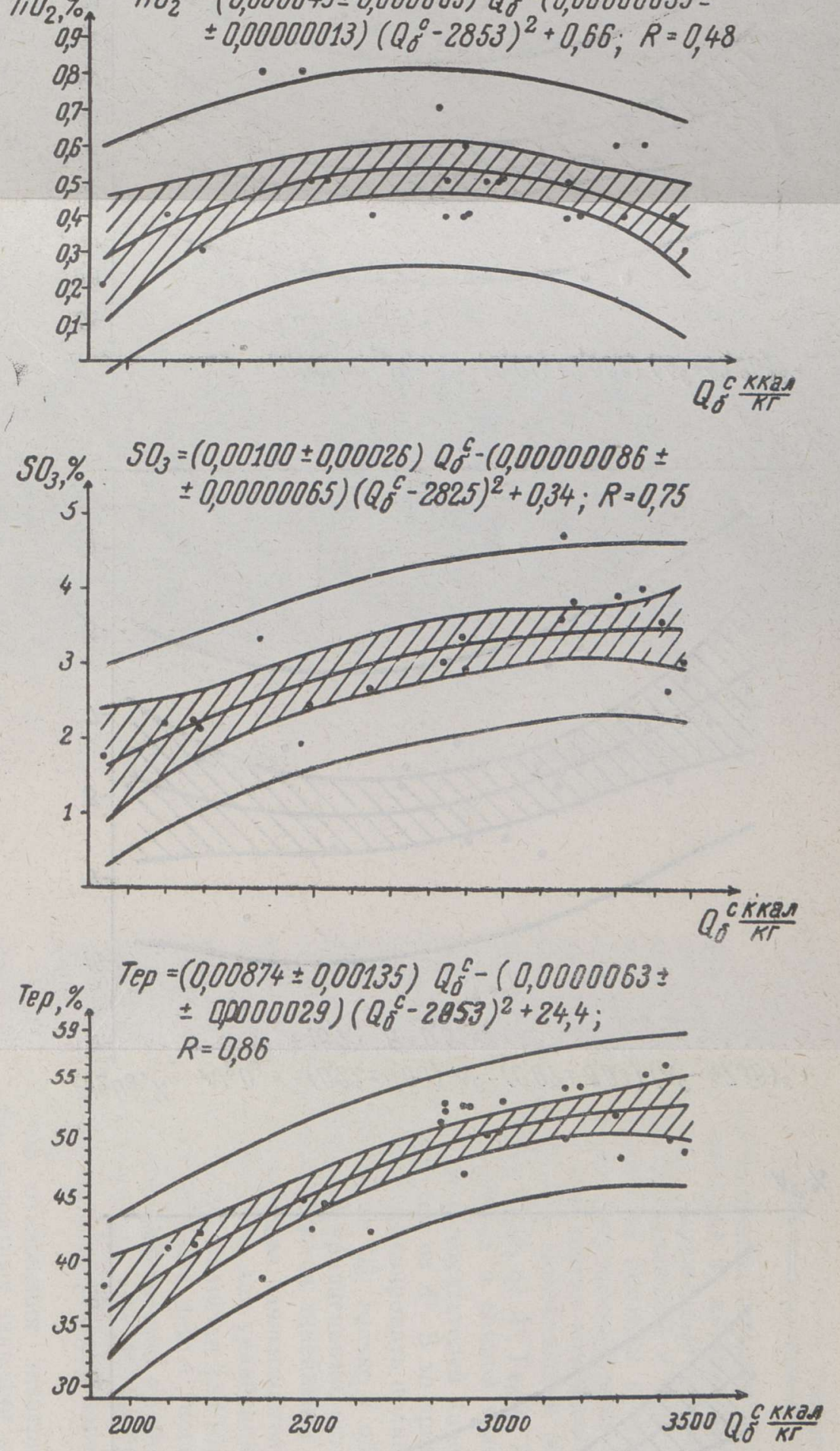

Рис. 2. Зависимости показателей качества горючих сланцев от теплотворной способности $Q_{6}^{\mathrm{c}}$. Обозначения см. рис. 1 . 


\section{A. SOKOLOVER}

\section{PÓLEVKIVI KVALITEEDI NÄITAJATE VAHELISED SOLTUVUSED}

Esitatakse energeetilise kaubapõlevkivi tuhasisalduse $\left(A^{c}\right)$ ja kalorsuse $\left(Q_{6}^{c}\right)$ ningpõhikvaliteedi ja ainelise koostise vahelised sõltuvused $\left(Q_{6}^{\mathrm{c}}, Q_{\mathrm{H}}^{\mathrm{p}},\left(\mathrm{CO}_{2}\right)_{\mathrm{K}}^{\mathrm{c}}, A^{\mathrm{c}}\right.$ ning tuha keemilise koostise komponendid $\mathrm{CaO}, \mathrm{MgO}, \mathrm{SiO}_{2}, \mathrm{Fe}_{2} \mathrm{O}_{3}, \mathrm{Al}_{2} \mathrm{O}_{3}, \mathrm{TiO}_{2}$ ja $\mathrm{SO}_{3}$ ), mis pakuvad huvi kaubapōlevkivi kompleksse kasutamise seisukohast. Sõltuvused $Q_{6}^{c}$-st on suurema tähtsusega kui sõltuvused $A^{c}$-st. Muutes kaubapõlevkivi $Q_{6}^{c}$, võib muuta ka teisi tema näitajaid.

\section{A. SOKOLOVER}

\section{DEPENDENCES BETWEEN THE QUALITY INDICES OF OIL SHALE}

In the article dependences are adduced, connected with the ash and calorific value of oil shale, used for power generation, as well as the indices of chemical composition which are of interest for a complex utilization of oil shale: the heating value (of dry and "as, received"fuel), carbonate dioxide, ash content, chemical components of ash (CaO, MgO, $\mathrm{SiO}_{2}, \mathrm{Fe}_{2} \mathrm{O}_{3}, \mathrm{Al}_{2} \mathrm{O}_{3}, \mathrm{TiO}_{2}, \mathrm{SO}_{3}$ ). The dependences in connection with the heating value a:e of a greater significance than those connected with the ash percentage. By changing the heating value of oil shale, it is possible to regulate its other indices. 